\title{
End-of-life care for COPD patients
}

\author{
*Mervyn M Dean ${ }^{\mathrm{a}}$ \\ a Palliative Care Physician, Western M emorial Regional Hospital, Western Health Authority, Newfoundland \& Labrador, Canada
}

Received 15th May 2007; revised version received 6th December 2007; accepted 11th January 2008

\begin{abstract}
Summary for COPD patients.

(c) 2008 General Practice Airways Group. All rights reserved.

MM Dean. Prim Care Resp J 2008; 17(1): 46-50.

doi:10.3132/pcrj.2008.00007
\end{abstract}

Patients with chronic obstructive pulmonary disease (COPD) receive poor end-of-life (EoL) care, in part because their disease course is not predictable. If the family physician would not be surprised at the patient's death within a year, then EoL issues should be raised for discussion. Embarking on such a discussion has the potential to enhance the patient's quality of life and EoL care, thereby avoiding unnecessary treatments or interventions. An Advance Health Care Directive can be useful. Appropriately-used systemic (not nebulised) opioids are safe and effective for managing dyspnoea. The family physician is in an excellent position to provide comprehensive EoL care

Keyw ords palliative care, end-of-life care, COPD

\section{Background}

Our ability to "do everything possible" in order to continue life is in direct conflict with "doing the right thing."

Patients with chronic obstructive pulmonary disease (COPD) follow a slowly-declining disease trajectory, punctuated by acute episodes of ill health, until the acute episode that proves to be the fatal one. ${ }^{2}$ When this final event occurs, family members may see the death as sudden and unexpected because no-one had spoken about the likely course of events with the patient and/or his or her family. ${ }^{3}$ COPD patients in their last year of life are likely to suffer from chronic dyspnoea (98\%), fatigue or weakness $(96 \%)$, low mood $(77 \%)$ and pain $(70 \%)$. Of these symptoms, dyspnoea is partly relieved in $50 \%$, but low mood is relieved in only $8 \%$ of cases and not treated in $82 \% .^{3}$ M urray has identified the challenge of palliative care for COPD patients ${ }^{4}$ and at least one UK regional group has taken up the challenge. ${ }^{5}$ Other authors have also started the process of discussing end-of-life (EoL) care for COPD patients. ${ }^{6,7}$ Many of these patients in my experience will have co-morbidities that need management alongside their COPD, but the focus of this paper is on the management of the patient's COPD.

The clinical course for COPD patients near the end of life cannot be predicted accurately, but EoL care is still possible. The challenge is to know when to introduce discussion of these topics despite the uncertain survival prognosis. A systematic review looking at when to introduce palliative care for patients with non-malignant conditions confirmed that in the case of COPD, an $\mathrm{FEV}_{1}$ value $<30 \%$, abnormal blood gases, and cor pulmonale with pulmonary hypertension, were predictors of a poor prognosis. ${ }^{8}$ However, the authors went on to say that $\mathrm{FEV}_{1}$ may not be the single most important parameter. Other prognostic factors were dyspnoea (measured on the UK Medical Research Council dyspnoea scale), muscle mass (not body weight), health status (measured by the St. George's Respiratory Questionnaire [SGRQ]) and exercise capacity (measured by peak $\mathrm{VO}_{2}$ ). ${ }^{8}$

These are not measures easily obtained in family or general practice, although they are useful if they are already on file. A stratagem more appropriate for the family physician is to ask himself/herself whether or not they would be surprised if the patient under consideration died within the next year (or perhaps six months) due to their COPD. ${ }^{9}$ This is not a question specific to COPD patients, nor is it an accurate prognostic question, but if the answer is "no", the physician should consider introducing discussion about the future course of the disease and dealing with EoL issues.

\footnotetext{
* Corresponding author: Palliative Care Department, Western Memorial Regional Hospital, Box 2005, Corner Brook, NL, Canada, A2H 6J7 Tel: 001 (709) 6375000 X 5487 Fax: 001 (709) 6375380 E-mail: mdean@healthwest.nf.ca
} 
As well as the general principles of EoL care, ${ }^{10,11}$ there are areas specific to COPD EoL care that have been considered by different studies. ${ }^{12,13}$ One study found that for any patient and their family to experience a "good death", six conditions are required: freedom from distressing symptoms; participation in treatment decisions; planning and preparation for death; completion of life with faith and spiritual experiences; resolution of conflicts; and affirmation as a whole person by caregivers. ${ }^{10} \mathrm{~A}$ second study listed the important elements as: trust in the treating physician; avoidance of unwanted life support; effective communication; continuity of care; and life completion. ${ }^{11}$ In a study comparing the needs of patients with cancer, AIDS or COPD, five areas specific to patients with COPD were identified: diagnosis and disease process; treatment; prognosis; what dying might be like; and advance care planning. ${ }^{14}$ Good EoL care enhances the patient's quality of life, optimises functioning, helps with decision-making, and provides opportunities for personal growth. ${ }^{15}$

Although communication underpins the above, EoL discussions are not easy to introduce or to conduct. One study of EoL communication found that $75 \%$ of patients wanted to focus on staying alive and not talk about dying ${ }^{16}$ but another study showed that a half of COPD patients wanted health professionals to talk with them about their disease and prognosis. ${ }^{17}$ This difference may be due to timing and the perceived attitude of the provider of the information ${ }^{18}$

Another barrier was a patient's uncertainty about the care they would want "if I get very sick", and about who would be looking after them - i.e. a fear of abandonment by their regular physician. ${ }^{16}$ Patients were more likely to enter into EoL discussion if they had friends or family who had died, had trust in their doctor, and confidence that their doctor had experience in the care of lung disease and cared about "me as a person" ${ }^{16}$ In this study, 11 of 15 barriers were endorsed by $10 \%$ of patients, but only two were endorsed by more than $50 \%$ of patients. Such heterogeneity among patients means that the physician needs to identify each patient's different concerns about EoL issues. There is no "one size fits all" solution.

For physicians the barriers were too little time, concern about taking away hope, and concern that "the patient is not ready to talk about [this]". The physicians were more likely to start EoL discussion if there was a good relationship with the patient, if they had cared for many patients with lung disease, and if the patient had been very sick in the past. ${ }^{16}$

Patients with lung cancer fare better, in terms of EoL care, than patients with COPD, despite their symptoms and needs being so similar. ${ }^{19}$ COPD patients had worse functioning in terms of activities of daily living (ADL), as well as worse physical, social and emotional funtioning. Family physicians are in an excellent position to begin to address the needs of these patients.

\section{Introducing EoL discussion}

Both physicians and patients find EoL issues difficult to discuss, ${ }^{16}$ although once discussion is started many patients appreciate it. For the physician, a useful indication to consider introducing EOL discussion is the "surprise question" ("Will I be surprised if this patient dies within the next six - or twelve - months?" ). ${ }^{9}$ Should the patient prefer to "focus on living, not dying", the physician should acknowledge the patient's discomfort with the topic, confirm that it is an important area to discuss, and keep in mind that not all patients will be ready for such a discussion the first time it is broached. ${ }^{17}$ However, raising the subject informs the patient that when he or she is ready, their physician is willing to discuss EoL topics.

\section{Discussion topics}

There are three primary areas to be covered: likely disease course and survival prognosis; advance health care directives; and symptom management. In addition, psychosocial and spiritual concerns should be addressed, by appropriate referral if necessary. These topics can be addressed over several visits, and often other family members will want to be involved.

\section{Disease course and survival prognosis}

This can be a difficult topic for both patient and physician to face. in my experience, patients are often very much more aware of their state of health than they are given credit for. In studies of prognosis discussions, many (cancer) patients have stated that it is the responsibility of the physician to introduce the topic. ${ }^{20,21}$ It is not easy to start to tell a patient - often a patient with whom one already has a long and close relationship - that he or she is going to become more breathless, less and less able to partake in any physical activity, and has an unpredictable future that includes the possibility of dying within a year.

There is no standard way to start, but my preference is for an open question, such as "Do you have any concerns about how things are going, or what's going to happen to you?" If the patient indicates that they would like such a discussion I start with a "WPC" approach - Warn, Pause, Check (WPC). For example, if the patient has said that they would like to know what the future holds, I might warn, "I'm afraid it is not good news." I then pause. It is likely that the patient already knows the news will not be good, and may say so. If the patient says nothing, I check by asking if I can continue - I have rarely had a patient say not to continue. I might use a couple of WPCs to gauge how much the patient wants to know, and then get into a frank but compassionate discussion, letting the patient know that they can stop the discussion at any time.

In my experience as a palliative care physician, it is rare that the patient does not want this discussion, but I only see 
patients who have been told that they are being referred for palliative care in the first place. If a patient does not want to have such a discussion the physician should consider what the reason (barriers) might be. ${ }^{16}$

Much of the literature on breaking bad news advises that someone be with the patient, and although this is not always possible at the first visit, one can always suggest that the patient does bring someone with them next time, especially as the patient's spouse and/or children will be likely to have some questions. Discussion should not focus only on the negative. For example, the physician can assure the patient that symptoms such as depression, pain and breathlessness can be managed, and the patient should focus on making the most of the time they have left, while allowing for the uncertainty of their survival prognosis. Decision-making as the disease progresses is easier if physician, patient and family members have already discussed the patient's goals, values, and wishes. Which brings us to the next topic...

\section{Advance Health Care Directive (AHCD)}

A properly drawn up AHCD is a useful document for the patient, the family and the health care staff. ${ }^{22}$ Unfortunately, many are so vague as to be useless, and even a well written AHCD is useless if it is not in the right place at the time it is needed - over $10 \%$ of AHCDs may not be on the hospital chart. ${ }^{23}$ I recommend that copies of the AHCD be kept at home, with the family physician, with the respirologist (if involved in management), and on any hospital chart where the patient is likely to be treated or admitted the physician should be familiar with any legislation in their country concerning AHCDs, and should be familiar with any national guidelines for deciding whether or not to provide cardiopulmonary resuscitation for a particular patient. Similarly, legislation varies from country to country as to who has responsibility for determining treatment for a noncommunicating patient. A helpful summary of the issues to be considered are in Neerkin \& Riley's paper. ${ }^{1}$

Even with a good AHCD, the patient should also discuss with their physician not only what their treatment wishes are, but also their goals and values in life e.g. surviving for an anniversary or wedding, or at what level of performance status the patient would anticipate wanting only "comfort measures". For the COPD patient, discussion of the acceptability of the variety of ventilatory supports available and limits on their duration of use - is important.

\section{Symptom management}

It is, as always, worth reviewing the patient's medication, ensuring as far as possible that the patient is taking all of their COPD medication correctly and that doses are optimised for that individual. As these patients often have one or more comorbidities the physician should also review the remaining medication. For example, if the patient clearly has a short survival prognosis, prophylactic anti-platelet and lipidlowering drugs are unnecessary.

For patients who are markedly dyspnoeic on maximum medication, consider opioids. The effectiveness of these drugs in treating dyspnoea in cancer and COPD patients is now well established, ${ }^{24-26}$ but they are disappointingly underused. Fears of causing respiratory depression or worsening blood gas measurements are unfounded. ${ }^{24}$ My practice is to use lower starting doses than those used for pain control, but then to use the same four-hourly dosing interval e.g. immediate release morphine $2.5 \mathrm{mg}$ (or even $1.25 \mathrm{mg}$ ) orally every 4 hours, plus an hourly breakthrough as-needed (PRN) order for $50 \%$ of the regular dose. The dose can be increased every few days until symptomatic improvement is obtained. Such improvement can be dramatic, and in my experience it is rare for an opioid-naïve patient initially to need more than $7.5 \mathrm{mg}$ 4-hourly. Once stable dosing is reached, the switch to a longacting opioid can be made. Any patient prescribed an opioid should, with few exceptions, be prescribed a laxative at the same time. Although there are some that still advocate the use of nebulised morphine ${ }^{25}$ there is substantial evidence showing it to be no better than placebo, ${ }^{26,27}$ and it is now not recommended. 28,29

To reduce a patient's dyspnoea further, midazolam has been used along with an opioid in severely dyspnoeic, hospitalised cancer patients, ${ }^{30}$ but has not been studied in COPD patients. My experience is that midazolam is a very useful adjunct for the end-stage COPD patient. Starting doses are usually $2.5 \mathrm{mg}$ to $5 \mathrm{mg}$ subcutaneously 2 -hourly PRN, or $10-30 \mathrm{mg} / 24$ hours via a continuous subcutaneous infusion. ${ }^{31}$ Earlier in the disease course longer-acting oral benzodiazepines can be used to ease the anxiety that often accompanies dyspnoea. For the end-stage patient at home and unable to take oral medication midazolam injection liquid is well-absorbed buccally. ${ }^{32,33}$

Oxygen is, of course, used judiciously so as not to diminish the hypoxic drive by which many of these patients survive. Other non-pharmacologic measures include positioning, and a flow of air from a fan or open window over the trigeminal area of the face. The patient will know what position is comfortable for them, but a severely dyspnoeic patient may not be able to communicate this. In the majority of cases a "half-Fowlers" position, sitting up in bed with the hips at an angle of between 30 and 60 degrees, is acceptable.

Early or persistent fatigue is a concern for many patients with advanced disease. Anemia and hypoxemia should be considered, but sometimes the only remedy is to advise patients to "pace" themselves through the day with adequate rest periods. Sleep can also be a problem, but often resolves when symptoms such as dyspnoea and pain are adequately addressed. 
Many patients who are terminally ill with end-stage lung disease are troubled with a cough with purulent sputum production. Prolonged antibiotic courses are not indicated here but ceftriaxone $(500 \mathrm{mg}$ with $0.5 \mathrm{ml}$ lidocaine $1 \%$ ) can be given as a one-time subcutaneous injection ${ }^{34}$ with, in my experience, considerable benefit. For the very troublesome non-productive cough that is not relieved by standard strategies (bronchodilators, opioids, mucolytics, etc.), consider nebulised lidocaine, ${ }^{35}$ but use of a bronchodilator prior to the lidocaine is necessary to avoid inducing bronchospasm. ${ }^{36}$ There may also be a role for sodium cromoglycate in relieving troublesome non-productive cough. ${ }^{37}$

One of the most troublesome symptoms for the family members of a dying patient is the presence of upper respiratory tract secretions - the "death rattle". The hyoscine group of drugs have long been used for this, and are quite effective, but glycopyrronium $(0.4 \mathrm{mg}$ subcutaneously 6 hourly PRN, or continuous infusion of $0.6 \mathrm{mg}-2.4 \mathrm{mg} / 24 \mathrm{hr}$ ) has been shown to be less sedating, and somewhat more effective. ${ }^{38,39}$ There are anecdotal reports of using atropine $0.1 \%$ eye drops sublingually (2-4 drops SL 2 -hourly PRN) with effect, which could be useful for families caring for a patient at home.

For the extremely dyspnoeic, agitated, hypoxic patient, sedation may be needed. This is a controversial procedure, but when used properly is an appropriate palliative treatment. ${ }^{40}$ Opioids should not be used as primary sedative medication. Although other drugs such as phenobarbital or levomepromazine (methotrimeprazine) can be used, my practice is to use midazolam either by intermittent subcutaneous injection $(2.5-5.0 \mathrm{mg} 2$-hourly PRN, but tolerance quickly develops, so be prepared to titrate upwards quite rapidly) or by continuous infusion based on the previous $24 \mathrm{hr}$ requirement (but again, be prepared to titrate the dose upwards quite rapidly). The subcutaneous infusion should use a concentration that delivers a volume of no more than $4 \mathrm{mls} / \mathrm{hr}$, and a breakthrough dose of half the hourly rate can be provided every 30 minutes. The aim here is patient comfort, not sedation to unconsciousness. ${ }^{40}$ The sedation is proportional to the symptom(s) i.e. just enough sedation to make the patient comfortable. I very rarely have had to sedate a dyspnoeic patient to unconsciousness.

Besides the physical symptoms, it is important to address the psychosocial and spiritual aspects of EoL care, including screening for depression. ${ }^{3}$ The physician should enquire into concerns about stresses at home, not only for the patient but for the caregiver(s) as well. Patients are often not so much frightened of dying, but are frightened of the process itself. Referral to appropriate social workers/counsellors or religious/faith leaders should be made with the patient's permission. It is likely that the caregiver(s) will be patient(s) of the physician as well, but even if not, it is important to ask about their concerns, and address them either directly or by referral, and to be generally supportive at what is a difficult time for them.

Many palliative care services are now branching out to provide service to patients with terminal non-malignant disease. The family physician/general practitioner should know what services are available for the patient. Palliative care is a team effort, and for the COPD patient the family physician should be a key member of that team. As well as recruiting spiritual leaders, counsellors, etc., palliative care physicians can also be consulted. Few of us bite (!), and most of us are delighted to be asked to help...

\section{Conflict of interest declaration}

The author has received payment from pharmaceutical companies (Purdue and Janssen Ortho) for presentations on cancer pain management. He has previously received (more than six years ago) payment from AstraZeneca and GlaxoSmithKline for presentations on asthma management.

\section{References}

1. Neerkin J, Riley J. Ethical aspects of palliative care in lung cancer and end stage lung disease. Chron Respir Dis 2006;3:93-101.

2. Murray SA, Kendall M, Boyd K, Sheikh A. Illness trajectories and palliative care $B M+2005 \cdot 330: 1007-11$.

3. Elkington $\mathrm{H}$, White $\mathrm{P}$, Addington-Hall J, Higgs R, Edmonds $\mathrm{P}$. The healthcare needs of chronic obstructive pulmonary disease patients in the last year of life. Palliat Med 2005;19:485-91.

4. Murray SA, Pinnock H, Sheikh A. Palliative care for people with COPD: we need to meet the challenge. Prim Care Resp J 2006;15:362-4. doi:10.1016/ j.pcrj.2006.08.008

5. O'Kelly N, Smith J. Palliative care for patients with end-stage COPD (letter). Prim Care Resp J 2007;16:57-8. doi:10.3132/pcrj.2007.00003

6. Seamark DA, Seamark CJ, Halpin DMG. Palliative care in chronic obstructive pulmonary disease: a review for clinicians. J Royal Soc Med 2007;100:225-33.

7. Goodridge D. People with chronic obstructive lung disease at the end of life: a review of the literature. International J Palliat Nursing 2006;12:390-6.

8. Coventry PA, Grande GE, Richards DA, Todd CJ. Prediction of appropriate timing of palliative care for older adults with a non-malignant life-threatening disease: a systematic review. Age Ageing 2005;34:218-27.

9. Lynn J, Schall MW, Milne C, Nolan KM, Kabcenell A. Quality improvements in end of life care: insights from two collaboratives. Jt Comm J Qual Improv 2000:26(5):254-67.

10. Steinhauser KE, Clipp EC, MCNeilly $M$, et al. In search of a good death; observations of patients, families and providers. Ann Intern Med 2000; 132:825-32.

11. Heyland DK, Dodek P, Rocker G, et al. What matters most in end-of-life care: perceptions of seriously ill patients and their family members. CMAJ 2006;174(5):627-33.

12. Varkey B. Unfulfilled palliative care needs of chronic obstructive pulmonary disease patients. Curt Opin Pulm Med 2006;12:103-05.

13. Pang SMC, Chan K-S, Chung BPM, et al. Assessing quality of life of patients with advanced chronic obstructive pulmonary disease in the end of life. J Palliat Care 2005;21:180-7.

14. Curtis JR, Wenrich MD, Carline JD, Shannon SE, Ambrozy DM, Ramsey PG. Patients' perspectives on physician skill in end-of-life care. Difference between 
patients with COPD, cancer, and AIDS. Chest 2002;122:356-62.

15. National Consensus Project for Quality Palliative Care. Clinical practice guidelines for quality palliative care, executive summary. J Palliat Med 2004;7:611-27.

16. Knauft E, Nielsen EL, Engelberg RA, Patrick D, Curtis JR. Barriers and facilitators to end-of-life care communication for patients with COPD. Chest 2005;127:2188-96.

17. Robinson T. Living with severe hypoxic COPD: the patients' experience. Nurs Times 2005;101:38-42

18. Kirk P, Kirk I, Kristjanson LJ. What do patients receiving palliative care for cancer and their families want to be told? A Canadian and Australian qualitative study BMJ 2004;328:1343. doi:10.1136/bmj.38103.423576.55

19. Gore JM, Brophy CJ, Greenstone MA. How well do we care for patients with end-stage chronic obstructive pulmonary disease (COPD)? A comparison of palliative care and quality of life in COPD and lung cancer. Thorax 2000;55:1000-06

20. Sahm S, Will R, Hommel G. What are cancer patients' preferences about treatment at the end of life, and who should start talking about it? A comparison with healthy people and medical staff. Support Care Cancer 2005;13:206-14.

21. Lamont EB, Siegler M. Paradoxes in cancer patients' advance care planning Palliat Med 2000;3:27-35.

22. Cartwright $\mathrm{CM}$, Parker $\mathrm{MH}$. Advance care planning and end of life decision making. Aust Fam Physician 2004;33:815-19.

23. Allen R, Ventura N. Advance directives use in acute care hospitals health law Ethics Regul 2005;7:86-91.

24. Bruera ref Bruera E, Macmillan K, Pither J, MacDonald RN. Effects of morphine on the dyspnea of terminal cancer patients. J Pain Symptom Manage 1990; 5:341-4.

25. Westphal CG, Campbell ML. Nebulized morphine for terminal dyspnea. Am J Nurs 2002;Suppl:11-15.

26. Jankelson D, Hosseini K, Mather LE, Seale JP, Young iH. Lack of effect of high doses of inhaled morphine on exercise endurance in chronic obstructive pulmonary disease. Eur Respir J 1997;10:2270-4.

27. Bauford W, Saylor TT, Stansbury DW, Avalos K, Light RW. Effects of nebulized morphine sulfate on the exercise tolerance of the ventilatory limited COPD patient. Chest 1993;104:175-8,

28. Foral PA, M alesker MA, Huerta G, Hilleman DE. Nebulized opioids use in COPD. Chest 2004;125:691-4.

29. Brown SJ, Eichner SF, Jones JR. Nebulized morphine for relief of dyspnea due to chronic lung disease. Ann Pharmacother 2005;39:1088-92.

30. Navigante AH, Cerchietti LC, Castro MA, Lutteral MA, Cabalar ME. Midazolam as adjunct therapy to morphine in the alleviation of severe dyspnea perception in patients with advanced cancer. J Pain Symptom Manage 2006;31:38-47.

31. Twycross R, Wilcock A, eds. Central Nervous System. In: Hospice and Palliative Care Formulary USA palliativedrugs.com Ltd. 2006:92

32. Scott RC, Besag FM, Boyd SG, Berry D, Neville BG. Buccal absorption of midazolam:pharmacokinetics and EEG pharmacodynamics. Epilepsia 1998;39(3):290-4

33. Lim TW, Thomas E, Choo SM. Premedication with midazolam is more effective by the buccal than oral route. Can J Anaesthesia 1997;44(7):723-6.

34. Borner K, Lode H, Hampel B, Pfeuffer M, Koeppe P. Comparative pharmacokinetics of ceftriaxone after subcutaneous and intravenous administration. Chemotherapy 1985;31:237-45.

35. Udezue E. Lidocaine inhalation for cough suppression. Am J Emerg Med 2001;19:206-07.

36. MCAlpine LG. Thomson NC. Lidocaine-induced bronchoconstriction in asthmatic patients. Relation to histamine airway responsiveness and effect of preservative. Chest 1989;96:1012-15.

37. Moroni M, Porta C, Gualtieri G, Nastasi G, Tinelli C. Inhaled sodium cromoglycate to treat cough in advanced lung cancer patients. Brit J Cancer 1996;74:309-11.

38. Hugel H, Ellershaw J, Gambles M. Respiratory tract secretions in the dying patient: a comparison between glycopyrronium and hysocine hydrobromide. J Palliat Med 2006:9:279-84.

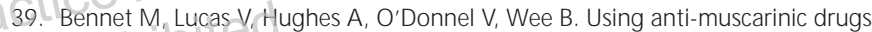
in the management of death rattle:evidence-based guidelines for palliative care. Palliative Medicine 2002;16:369-74.

40. De Graeff A, Dean M. Palliative sedation therapy in the last weeks of life: a literature review and recommendations for standards. J Palliat Med 2007;10: 67-85.

Available online at http://ww w.thepcrj.org 